\title{
A LEGISLAÇÃO AFONSINA E A PRÁTICA DA MEDICINA NA CASTELA DO SÉCULO XIII
}

\section{Afonsine legislation and the practice of medicine in 13th century Castile}

\author{
Profa. Dra. Marta de Carvalho Silveira \\ Docente de História Medieval da \\ Universidade do Estado do Rio de Janeiro (UERJ) \\ Email: martadecarvalhosilveira@gmail.com \\ ORCID: https://orcid.org/0000-0002-3757-7853
}

Recebido em: 18/10/2020

Aprovado em: 17/01/21

\begin{abstract}
Resumo: Para pôr fim à pluralidade jurídica que caracterizava o reino castelhano no século XIII e levar adiante o seu projeto de centralidade do poder monárquico, Fernando III e Afonso X investiram na elaboração de novas bases legais para regular o convívio social e favorecer o reconhecimento da autoridade real. Tais obras jurídicas tiveram fundamentalmente o papel de ordenar a convivência social e de favorecer o reconhecimento da autoridade régia sobre diversos assuntos, inclusive sobre as questões relativas à saúde. Esse trabalho objetiva, através da análise de algumas das fontes legislativas, identificar a política monárquica castelhana prevista para a regulação da prática médica e a garantia da saúde dos habitantes do reino.

Palavras chaves: Monarquia castelhana; saúde pública; corpo; fueros.

Abstract: In order to put an end to the legal plurality that characterized the Castilian kingdom in the 13th century and to carry out their project of centrality of monarchical power, Fernando III and Afonso X invested in the elaboration of new legal bases to regulate social coexistence and favor the recognition of the royal authority. Such legal works had the fundamental role of ordering social coexistence and favoring the recognition of the royal authority on several subjects, including on matters related to health. This work aims, through the analysis of some of the legislative sources, to identify the Castilian monarchic policy foreseen for the regulation of medical practice and the guarantee of the health of the inhabitants of the kingdom.
\end{abstract}

Keywords: Castilian monarchy; public health; body; fueros. 
Como parte de um projeto de busca pela centralidade do poder monárquico, em virtude da reunificação dos reinos de Leão e Castela por Fernando III (1201-1252), iniciou-se na corte real um processo de retomada e de ressignificação da tradição legislativa visigoda, com a elaboração do Fuero Juzgo, e de formulação de uma ampla base legal produzida na corte de Afonso X (1221-1284), com a redação de obras como o Fuero Real e as Sete Partidas e com a confirmação de fueros já existentes, como o Fuero de Burgos.

O objetivo desse trabalho é analisar a forma como a monarquia castelhana regulamentou a prática da medicina realizada pelos físicos, regulamentando a formação dos físicos, normatizando a prática da medicina e estabelecendo a legalidade de alguns procedimentos profiláticos. Para tanto, serão utilizadas algumas das fontes jurídicas castelhanas produzidas nos séculos XIII e XIV: o Fuero Juzgo, o Fuero Real, as Sete Partidas e o Fuero de Burgos ${ }^{l}$.

Pretende-se considerar aqui os princípios legais estabelecidos pela monarquia castelhana na formulação de uma política pública de saúde que pretendia, em última instância, assegurar a qualidade do tratamento médico oferecido à população e identificar o monarca como o ordenador da saúde do corpo social. A garantia da saúde física dos súditos e do monarca era entendida como uma estratégia para assegurar a prosperidade do reino e a sua estabilidade política.

A seleção dos códigos jurídicos apontados como fontes de pesquisa para esse trabalho se explica pelo fato de terem sido eles representativos, tanto em termos dos princípios normativos determinados quanto pela extensão da sua aplicação em termos territoriais na Castela do século XIII.

Para organizar a exposição das conclusões alcançadas nesse trabalho inicialmente as obras legislativas foram caracterizadas e relacionadas ao seu contexto de produção. Em seguida, as determinações legais relativas ao ordenamento da prática médica foram analisadas a partir dos códigos selecionados, e as conclusões reunidas no final desse texto.

Uma perspectiva teórica voltada para o campo da nova história política baseou as reflexões realizadas aqui. Motivados a precisar o campo dos estudos políticos no conjunto das estruturas históricas, a ampliar o leque do entendimento das temáticas 
relativas a esse campo e a propor a intensificação do debate interdisciplinar para a sua análise, os historiadores que investiram na renovação do campo do político, especialmente a partir da década de 1980, se voltaram para explorar novas perspectivas de pesquisa. Nas palavras de René Remond, um dos principais articuladores dessa renovação:

[...] Cada vez menos pesquisadores acham que infra-estruturas governam superestruturas, e a maioria prefere discernir (como os autores deste livro) uma diversidade de setores - o cultural, o econômico, o social, o político que se influenciam mútua e desigualmente segundo as conjunturas, guardando ao mesmo tempo, cada um sua vida autônoma e seus dinamismos próprios. (REMOND, 2003:10)

Entendendo a necessidade de interlocução do campo do político com os demais elementos estruturais, Remond situou-o no estudo das atividades que envolvem a conquista, o exercício e a prática do poder, mas não qualquer poder e sim aquele que se relaciona com o poder na sociedade global, definida como:

[...] aquela que constitui a totalidade dos indivíduos que habitam um espaço delimitado por fronteiras que chamamos precisamente de políticas. Na experiência histórica ocidental, ela se confunde com a nação e tem como instrumento e símbolo o Estado. [...] Entretanto, se o político é aquilo que tem uma relação direta com o Estado e a sociedade global, ela não se reduz a isso: ele se estende também às coletividades territoriais e a outros setores por esse movimento que ora dilata e ora encolhe o campo do político. (REMOND, 2003:444)

Portanto, na proposição dos partidários da nova história política, tal como a pensou Remond, o estudo do político se faz no enlace com as práticas sociais e com as estruturas simbólicas, sempre em busca das relações de poder que envolvem o governo de uma região e os demais atores sociais que manifestam comportamentos, elaboram símbolos, difundem ideias que se relacionam à sua perspectiva sobre o funcionamento adequado da sociedade em que vivem.

Seguindo o desafio proposto para um entendimento da história política numa perspectiva global, onde se estabelece um diálogo com os demais domínios da história, é que neste trabalho foram considerados os elementos da cultura intelectual constituída em torno do saber médico e do saber jurídico, buscando-se inferir as práticas sociais que 
sustentavam as proposições legais. Como alertou F. Hespanha, uma das maiores referências da "história crítica do direito", é preciso apostar nas conexões existentes entre a História e o Direito, mas sem tornar o conhecimento histórico como um meio de sacralização do Direito contemporâneo. Distanciando-se de uma perspectiva evolucionista das formas jurídicas, que se concentra na busca pelas origens dos mecanismos legais do Estado Moderno nas sociedades antiga e medieval, Hespanha propôs o seguinte entendimento acerca das normas jurídicas

[...] Antes de mais, as normas jurídicas apenas podem ser entendidas se integradas nos complexos normativos que organizam a vida social. Neste sentido, o direito tem um sentido meramente relacional (ou contextuais). $\mathrm{O}$ papel da regulação jurídica não depende das características intrínsecas das normas do direito, mas do papel que lhes é assignado por outros sistemas normativos que formam o seu contexto. Estes sistemas são inúmeros - da moral à rotina, da disciplina doméstica à organização do trabalho, dos esquemas de classificar e de hierarquizar às artes de sedução. O modo como eles se combinam na construção da disciplina social também é infinitamente variável. (HESPANHA, 2003:35).

Pretende-se neste trabalho, então, identificar e explorar as conexões existentes entre o processo normativo da monarquia castelhana referente à regulamentação da prática medicinal e ao exercício da física, as práticas sociais difusas na sociedade referentes ao tratamento das enfermidades, e ao múltiplo arcabouço cultural produzido na corte afonsina.

\section{Os códigos jurídicos e o contexto castelhano no século XIII}

O FJ, publicado em 1241, representou a primeira tentativa do rei Fernando III de garantir a unidade política e jurídica do reino castelhano-leonês recém-unificado. Esse código foi composto por mais de seiscentas leis, divididas em cinquenta e seis títulos ordenados em doze livros. De acordo com M. Bejder:

O Fuero Juzgo consistiu em um códice de leis promulgado em Castela, no ano de 1241, pelo rei Fernando III e atribuído à cidade de Córdoba. Na verdade, tratava-se de uma tradução para o castelhano do Líber Iudiciorum, um códice de leis escrito em latim, formulado em 654, pelos visigodos, sob forte influência do direito romano. (BEJDER, 2008:1). 
A luta pela manutenção da unidade do reino contra as forças centrífugas, especialmente as nobiliárquicas, não se esgotou com a morte de Fernando III, conforme mencionado anteriormente. Ainda como príncipe, Afonso X, viajava pelo reino garantindo ao seu pai não só significativas vitórias militares, mas também representatividade jurídica. Nicaso Salvador (SALVADOR, 1986) recorda que o príncipe Afonso presidiu algumas vezes os juízos na corte real e, a pedido do seu pai, mandou iniciar a redação do Setenário.

Apesar de todos os intentos unificadores do seu pai ao assumir o poder, Afonso $\mathrm{X}$ teve que lidar com o desafio de governar um reino ainda marcado por uma forte diversidade populacional e pela atuação de uma nobreza que exercia um poder efetivo sobre várias localidades do reino, valendo-se em grande parte das leis expressas na tradição foram local. Para garantir o respeito à sua autoridade frente à diversidade de poderes existentes nobiliárquicos, eclesiástico e municipais em seu reino, Afonso $\mathrm{X}$ mandou elaborar uma vasta obra jurídica que serviu como referência para outras produzidas em outras regiões do ocidente medieval.

A obra jurídica afonsina tem sido alvo de inúmeras pesquisas nos últimos anos, especialmente no campo da História do Direito, por tratar-se de um material extremamente rico e complexo. O entendimento da configuração interna desses códigos jurídicos e das relações existentes entre eles, a produção político-cultural do scriptorium afonsino e os outros códigos legais produzidos fora ou dentro da Península Ibérica tem sido investigados por vários pesquisadores. A variedade dos estudos relativos às fontes jurídicas afonsinas pode ser atestada fazendo-se uma simples pesquisa no Anuario de Historia del derecho español, publicação iniciada na década de 1920, ativa até hoje e disponível no site da Agência Estatal Boletim Oficial del Estado do Goberno de España, onde nota-se a presença de artigos clássicos e atuais.

R. Macdonald, em seu artigo Problemas políticos y derecho alfonsino (1984), publicado no Anuário, dividiu as obras jurídicas afonsinas em duas categorias principais: um grande corpo composto por uma legislação mais específica e um corpo menor formado por uma legislação mais geral. No primeiro tipo situou os fueros concedidos ou confirmados, os ordenamentos das Cortes (que consistiam em respostas oficiais às petições dirigidas ao rei), o esclarecimento das questões legais, os procedimentos judiciais que se remetiam aos concelhos, as cartas de privilégios, os 
regulamentos de atividades econômicas e os dois testamentos de Afonso X. O Setenário, o Fuero Real, o Especulo e as Sete Partidas constituem o segundo tipo de obra, justamente pela sua visão geral e abrangente das questões legais.

O projeto jurídico afonsino materializou-se em quatro grandes obras legislativas: o Especulo (também denominado Fuero del Libro, Libro del Fuero ou Libro del espejo de derecho), que foi dado às regiões de Castela e da Extremadura; o FR (inicialmente concedido às cidades de Castilla la Vieja, que estendeu-se progressivamente à Extremadura, à Transierra, ao reino de Toledo, à Andaluzia e a Murcia); as Sete Partidas que, ao contrário das obras anteriormente mencionadas, foi fruto de um esforço enciclopédico na definição das principais noções presentes no direito castelhano; e o Setenário, obra inacabada iniciada em 1251, marcada pela polissemia e por um caráter apologético à figura de Fernando III e demonstrando grande semelhança com as Partidas pelo seu caráter filosófico, místico e enciclopedístico. J. Valdeón constatou que: “[...] El Rey Sabio emprendió uma formidable obra de caracter jurídico, centrada en tres pilares fundamentales: el Espéculo, el Fuero Real y las Siete Partidas." (VALDEÓN, 1985:6).

O FR, cuja datação é incerta e polêmica, foi redigido em quatro livros, subdivididos em títulos e leis. No prólogo, seus leitores foram advertidos a observar a importância daquele código para a manutenção da paz e da ordem social. No primeiro livro foi explicada aos leitores a função da lei, da justiça e do rei na sociedade. No segundo livro, alguns procedimentos legais sobre a validade dos testemunhos, dos juramentos e dos juízos foram definidos. O terceiro livro legislava sobre as questões relativas a bens (fiadores e fiaduras, por exemplo) e a herança (como no caso do casamento e de situações a ele relacionadas: direito dos órfãos, das viúvas, dos filhos etc.). Já o quarto livro foi dedicado às questões penais relativas ao adultério, aos procedimentos considerados adequados aos físicos (pessoas que trabalhavam na cura de doenças), à falsificação, e outras questões consideradas importantes e passíveis de penalização. Para viabilizar a análise do tema estabelecido nesse trabalho, utilizou-se basicamente o livro quatro e considerou-se a proposição de Iglesia Ferreirós (1980) de que o FR e as Sete Partidas foram redigidas na corte afonsina e não em um período posterior (IGLESIA FERREIRÓS, 1980:560). 
Em termos de fontes jurídicas para o estudo do período medieval, as Partidas são sem dúvida a mais complexa e completa. Dada a sua importância, é possível encontrar versões impressas e digitalizadas dessa obra e diversos trabalhos, sendo explorada como fonte de pesquisa por historiadores e por juristas.

As Partidas foram organizadas em sete livros e possuem um índice geral e índices específicos para cada um dos livros. A Primeira Partida tratou das leis canônicas; a Segunda Partida definiu os direitos dos reis e da alta nobreza; a Terceira Partida cuidou da lei processual e da administração da justiça; a Quarta Partida se ateve à lei civil (sobretudo às questões matrimoniais e às relações humanas); a Quinta Partida focou mais nas questões comerciais; a Sexta Partida estabeleceu leis referentes ao direito patrimonial; e a Sétima Partida destinou-se às leis criminais.

Um diferencial dessa obra é justamente o seu caráter enciclopédico, visto que, ao contrário dos fueros, onde as leis foram organizadas de forma a conter basicamente a indicação de uma penalidade a um ato criminoso correlato, as Partidas estabeleceram discussões jurídicas e filosóficas em torno de temas e noções, promovendo o entendimento do porquê de um ato determinado ser considerado passível de punição para a garantia do bem social.

A outra fonte selecionada para análise foi o FB, um código legal que atravessou diversos reinados. A versão analisada aqui foi àquela concedida à cidade de Burgos por Afonso X. Burgos ocupou um lugar significativo na configuração dos reinos de Leão e Castela, sendo uma das municipalidades mais importantes, especialmente por ter feito parte, no século XII, do processo de repovoamento e pelo processo urbanização decorrente da retomada do caminho peregrinatório a Santiago de Compostela. A cidade mostrou-se uma peça fundamental no projeto político de revitalização da sociedade muçulmana e de retomada das terras dominadas pelos muçulmanos proposto por Afonso VI, por isso mesmo, recebeu um fuero próprio.

De acordo com Gilbert a cidade de Burgos foi povoada desde aproximadamente 880, havendo referências seguras de que, desde 1039, a cidade contou um fuero primitivo outorgado “[...] a los pueblos del monasterio de Cardefia: et /per suos iudicios foro burgensi, en to quc se podria entender la aplicacion de unas leyes o la sumision a unos juicios.” (GILBERT, 1961:710). Com a intensificação do repovoamento na região, Afonso VI outorgou aos moradores das vilas régias de Burgos um novo fuero, 
concedendo-lhes exceções e privilégios. Além disso, o monarca transferiu a sede episcopal de Oca para Burgos e garantiu-lhe a doação de um significativo patrimônio territorial. Contudo, a mais significativa concessão feita pelo monarca foi o direito de criar a sua própria jurisprudência que, com o passar do tempo, tornou-se uma referência jurídica para os municípios vizinhos, contribuindo para a fundação de uma das famílias forais mais significativa do reino. Como alertou Gilbert: “[...] Fundamentalmente, el derecho de Burgos fue recogido en redacciones privadas $\mathrm{v}$ anonimas, acaso en la hoy perdida yue sirvio de fuente al Lihro de los fueros de Castilla" (GILBERT, 1961:711).

O FB manteve-se vigente na cidade de Burgos e nas regiões circunvizinhas mesmo com a promulgação do FR por Afonso X, em 1256, onde algumas dúvidas dos alcaides locais foram apresentadas ao monarca, que encarregou os seus juristas de respondê-las. Com a deflagração da revolta de 1272, evidenciou-se o rechaço de setores significativos das municipalidades e da nobreza ao uso do FR, então, o rei concedeu às comunidades locais o direito de usar os antigos fueros outorgados no reinado de Afonso VIII. A versão aqui analisada é a que estava vigente no reinado de Afonso X.

Apresentados alguns elementos em torno da composição das obras e a sua conexão com o contexto do reino castelhano, é preciso considerar os fatores que explicam a sua seleção como fontes primárias para esse artigo. Os quatro códigos selecionados estiveram vigentes ou foram produzidos durante o reinado afonsino e isso contribui diretamente para que se possa estabelecer uma conexão entre o projeto de centralidade de poder e de ordenamento social proposto pela corte castelhana e a necessidade de regular a atividade dos físicos e a prática da medicina na garantia da saúde do corpo social. Um outro ponto que explica a seleção desse conjunto de fontes é o fato de que elas complementam umas às outras. $\mathrm{O} F J$ remete-se à tradição jurídica do reino, o FR expressa o projeto de centralidade do poder real proposto pela corte afonsina, as Partidas apresentam definições conceituais em torno de noções jurídicas e o FB traz consigo um conjunto de leis que envolve tanto as determinações reais quanto a memória legal da comunidade de Burgos reescrita e revisitada ao longo dos séculos.

Ao estabelecer-se a comparação dessa documentação, não se partiu de uma perspectiva hierárquica e nem se considerou as medidas como precursoras daquelas dos códigos modernos. Cada uma das leis analisadas foi entendida na especificidade do contexto político, cultural, social e econômico em que foram forjadas. $\mathrm{O}$ 
estabelecimento da regulamentação da prática médica foi o fio analítico comparativo, mas como alertou Kocka, sobre as abordagens comparativas, elas "[...] apenas enfatizam e, particularmente, fazem manifestar o que é implícito em qualquer tipo de trabalho histórico: um forte componente seletivo e construtivo" (KOCKA, 2003:4).

No mais, as fontes primárias elencadas foram compreendidas dentro da perspectiva enunciada por Paolo Grossi, ao considerar que a ordem jurídica medieval obedece, sobretudo, a uma constituição consuetudinária, mesmo que existissem tratados e glosas que apontassem para a formulação de noções gerais e intelectualmente depuradas sobre o direito. Na edição revisada da sua obra A Ordem Jurídica Medieval (2014), o autor afirma:

[...] A ideia central - vivamente expressa a partir do título - consiste em entender o direito como uma ordem subjacente, que deve ser lida nas tramas da natureza e da sociedade, que deve ser interpretada e reduzida a regras para a vida cotidiana.

E insisto também em afirmar a rejeição de esquemas interpretativos excessivamente impregnados de significados modernos e, portanto, alheios à civilização medieval e, por conseguinte, fonte de equívocos e até mesmo enganosos [,...] (GROSSI, 2014: XXII)

\section{A Península Ibérica como um espaço de produção de saberes médicos e jurídicos}

Seguindo o caminho apontado por Grossi, é possível reconhecer que, imerso na necessidade de retomar de grande parte do território peninsular das mãos da liderança muçulmana, de ocupar efetivamente os espaços conquistados e de unir as forças políticas dispersas no reino castelhanoleonês sob a liderança da sua corte, Afonso X deu continuidade ao projeto político inaugurado por seu pai. Para tanto, reconheceu nos mecanismos jurídicos os instrumentos necessários para basear a sua autoridade. Contudo, ao estabelecer as leis, o fez com base em uma forte tradição consuetudinária a qual aliou uma concepção organicista de poder bastante difundida nos meios intelectuais ocidentais desde o século XII.

As discussões em torno dos limites do exercício do poder real e principalmente da sua relação com o poder eclesiástico alimentaram várias obras produzidas no âmbito clerical desde a Alta Idade Média. Contudo foi João de Salisbury (1120-1180) que, em 
um contexto de intensa luta dos reis franceses pela centralidade de poder, refletiu mais profundamente sobre as dimensões que o poder real deveria alcançar na sociedade. Em sua obra Polycratus, finalizada em 1159 e considerada um dos principais tratados políticos produzidos no medievo, o autor aliou a sua teoria política às considerações morais que assegurariam a felicidade e a salvação dos cristãos. Salisbury utilizou uma metáfora já conhecida em seu tempo, para relacionar a organização política do reino e o corpo humano. Seguindo essa lógica, o monarca era considerado o cabeça do reino e responsável pela manutenção a integridade social, assegurando que todos os órgãos/ordens cumprissem a sua função para a manutenção da harmonia e da saúde social.

A obra de Salisbury se concentra em um contexto onde as reflexões engendradas no âmbito clerical buscavam responder às transformações experimentadas pelo ocidente medieval ao longo do século XII. A reforma eclesiástica do século XII, em busca da inserção efetiva da autoridade papal sobre o corpo clerical e sobre a sociedade como um todo, utilizou-se do estudo do Código Juris Civilis, reunido pelo imperador Justiniano, e de outras fontes do direito romano, em busca das bases jurídicas necessárias para a formulação do direto canônico e a consequente fundamentação do poder teocrático papal.

A formulação do direito canônico encontra-se profundamente relacionada à formação das escolas catedralícias e às universidades. No ambiente universitário, especialmente em Bolonha, o saber jurídico foi intensamente estudado. Autores clássicos da história do direito identificam o século XII como o ponto de virada para a formulação do Direito, chegando a denominar esse período como o do "renascimento do direito" e de formação de uma "ciência jurídica". Antonio Schioppa, autor da obra História do Direito na Europa. Da Idade Média à Idade Contemporânea (2014), faz as seguintes considerações em relação à produção jurídica medieval:

[...] A nova ciência do direito, cujas características veremos mais adiante, elaborada primeiramente em um único centro de estudos surgido na cidade de Bolonha e, depois aplicada em outras universidades italianas e europeias que adotaram seus métodos a partir do século XII, foi a matriz de um conjunto de normas e de doutrinas que assumiram a denominação de "direito comum". (SCHIOPPA, 2014:59) 
A importância da obra jurídica produzida após o século XII reside, sobretudo, na ampliação do contato com os textos gregos helenísticos e romanos. A intensa política de tradução destes textos e a formulação das glosas, comentários elaborados pelos tradutores a partir da leitura dos textos, fomentaram a elaboração de uma ciência do direito.

As reflexões jurídicas foram fortalecidas, no âmbito peninsular, pela ação dos tradutores toledanos. Os centros de saber localizados nas sedes episcopais, nas universidades e nas cortes reais ibéricas foram espaços de intensa produção de conhecimentos. O scriptorium afonsino foi identificado também pelos seus contemporâneos como o lugar de produção de uma vasta obra jurídica. Afonso X impulsionou, com financiamentos, a ação da escola de tradutores de Toledo, e fez um apelo aos estudiosos de língua árabe que participassem das atividades ali realizadas. Dessa forma, estudiosos de diversos locais do ocidente e do mundo muçulmano recorriam à escola em busca da tradução para o latim e para o castelhano dos textos clássicos e muitas vezes desconhecidos. Discutindo a importância da ação dos tradutores toledanos, Danielle Jacquart afirmou:

\footnotetext{
Cinquenta anos após a reconquista da cidade pelos cristãos, Toledo tornou-se um centro de traduções, cuja atividade não pode ser comparada a de nenhum outro na Idade Média latina. A presença de moçárabes e de judeus que conheciam o árabe, a possibilidade de ter à mão muitos manuscritos, atraíram eruditos de diferentes países da Europa. Mesmo que a denominação de "escola", durante tanto tempo utilizada, não pareça apropriada, houve, em Toledo, verdadeiras equipes de tradutores, que poderiam ser qualificados de "profissionais" (JACQUART,1992:155)
}

Foi através das traduções realizadas em Toledo e dos centros de tradução na Península Itálica que a obra de Aristóteles difundiu-se pelo ocidente medieval. A difusão dos textos aristotélicos nas universidades e nos demais centros de saber, alteraram a forma como o homem medieval relacionou-se com a produção do conhecimento, graças, em boa parte, à absorção dos seus princípios filosóficos por teólogos como Tomás de Aquino (1225-1274). Contudo é importante considerar o alerta de François Boustani quanto às traduções das obras aristotélicas que ganharam intensidade no ocidente a partir do século XII: "Uma das consequências mais importantes das traduções foi o retorno de Aristóteles ao Ocidente, um Aristóteles um pouco arabizado, 
um pouco hebraizado, depois de passar por espaços mentais diversos, como o dos analistas árabes e dos tradutores hebreus" (BOUSTANI, 2018: 85).

Duas concepções de entendimento do mundo físico e da ordem natural foram constituídas no pensamento cristão através da absorção da filosofia aristotélica: a ideia de que o macrocosmo se reproduzia no microcosmo e de que o conhecimento do mundo exterior (a natureza) redundaria em uma maior aproximação de Deus.

A busca pelo entendimento racional dos fenômenos naturais e da realidade passou a ser encarada como uma necessidade espiritual do ser humano em seu movimento de aproximação de Deus. O conhecimento era entendido como uma dádiva divina e considerado como a expressão da sabedoria de Deus, criador das leis naturais através das quais exprimia a sua ação sobre os homens. Conhecer, em última instância, era aproximar-se do esplendor da divindade.

Poucos textos aristotélicos haviam sobrevivido, no ocidente, à desagregação do Império Romano. Ao promover a sua expansão em direção ao oriente, os muçulmanos tiveram contato com a vasta herança cultural legada pela cultura helenística e preservada no mundo siríaco, situado ao norte da Síria, norte do Iraque e sudeste da Turquia, onde diversos estudiosos empreendiam a tradução dos textos do grego para o siríaco. Essa região era importante pela sua localização geográfica, justamente por estar situada entre o território bizantino e o território persa, sendo cruzada por uma série de rotas comerciais que partiam do Golfo Pérsico, do Egito e da China em direção à Ásia Menor, funcionando não só como um local de trocas produtos, como também de manuscritos.

O domínio persa sobre essa região angariou o apoio dos imperadores a essa atividade intelectual. Como informa Boustani: "Esse movimento viu seu apogeu sob o longo reinado do imperador persa Korsh I Anôcharvan (531-578), fundador da Escola de Gundishapur, que realiza a fusão das heranças siríaca, grega e indiana." (BOUSTANI, 2018:45). Além do patronato dos imperadores persas aos sábios tradutores, outro fator ajuda na compreensão da formação desses centros de traduções instalados no oriente e na bacia mediterrânica: a política adotada por alguns imperadores bizantinos que perseguiram sábios e filósofos gregos por condenações de heresia, promoveu uma verdadeira diáspora intelectual do mundo grego para os centros de saber que se formavam. O imperador Zenão, em 439, perseguiu vários filósofos pela 
heresia nestoriana, que migraram para Edessa após serem condenados no Concílio de Éfeso. Posteriormente, Justiniano mandou fechar a Academia de Platão e a Escola de Medicina, em 529, levando uma série de médicos a deixar a região e migrar para Gundishapur.

A expansão muçulmana para o oriente ampliou a realização de traduções dos manuscritos do siríaco para o árabe e a difusão desses manuscritos nas madrassas fundadas em diversas regiões a oriente e a ocidente do mundo muçulmano. Assim como se deu com os textos jurídicos, diversos tratados médicos greco-romanos, especialmente os de Hipócrates e Galeno, foram traduzidos e outros, como os de Ibn al-Nadim (morto em 987), Al-Kofty (1172-1248) e Ibn Ussayba (1220-1270) foram redigidos nesse ambiente intelectual marcado pelo dinamismo.

Um diferencial em relação à medicina árabe era a conciliação realizada entre a teoria e a prática. Os hospitais, fundados na maioria das vezes com o patrocínio dos califas, tinham tanto a função de tratar dos doentes, como também se tornarem espaços de elaboração do saber médico, na medida em que os resultados obtidos com os tratamentos ministrados eram redigidos e reunidos em novos tratados medicinais e em comentários às obras clássicas correntemente utilizadas.

Boustani identificou as várias escolas médicas que surgiram, após o século VIII, quando o mundo muçulmano experimentou sua primeira quebra de unidade política, com a queda dos omíadas, a instalação do califado de Córdoba e a ascensão dos omíadas. O autor especificou os personagens icônicos dessas escolas e as características da sua produção. No que se refere à escola da Andaluzia foi corrente o patrocínio oferecido pelos califas na aquisição de tratados médicos greco-romanos. Abd AlRhaman III (912-961), califa de Córdoba, tornou Al Andaluz uma das cortes mais culturalmente mais importante do período medieval alcançando, inclusive, o reconhecimento dos chefes de poder, como o imperador bizantino Constatino VII (905959), com que negociou manuscritos. Contudo, Danielle Jacquart e Boustani concordam em considerar que a medicina praticada nos anos iniciais da conquista muçulmana possuiu um caráter muito mais empírico do que teórico, mas que deu origem a algumas obras médicas como a de Albucasis, médico cordobês, que deixou registradas as suas anotações sobre as técnicas empregadas no tratamento dos seus pacientes. Como identificou Jacquart: 
[...] A medicina árabe da Espanha do século IX parece comprável à que conheciam então os países cristãos da Europa, exploram-se as mesmas fontes latinas: as Etimologias de Isidoro de Sevilha e, talvez, uma versão datando dos séculos V e VI dos Aforismos de Hipócrates. (JACQUART,1992:169)

Com a desagregação do califado de Córdoba, em 1031, o saber produzido na região, como apontado anteriormente, migrou para Toledo. Outro centro de traduções e de literatura médica bastante vibrante e contemporâneo ao de Córdoba foi montado na cidade de Salerno. Segundo a tradição, a Escola de Salerno foi fundada nos anos 900 por quatro médicos de origem étnica diversa: o grego Salernus, o latino Elinus, o judeu Adala e um médico árabe. Afora essa origem lendária, Salerno abrigou Constantino, o Africano, que realizou inúmeras traduções dos manuscritos árabes para o latim. A escola de medicina de Salerno foi a grande referência na tradução e na produção de tratados médicos, especialmente no campo da anatomia, e teve entre os seus principais expoentes, o italiano Ruggero de Frugardo (1120-1195), autor da obra Practica Chirurgiae, escrito por volta de 1170 , que serviu como uma referência para a prática cirúrgica até o período moderno.

As traduções realizadas na Península Itálica e na Península Ibérica ganharam os diversos centros de saber monacais, onde as obras recém adquiridas se somaram àquelas já presentes nas casas monásticas. As abadias reuniam os seus próprios tesouros intelectuais em seus scriptoria, traduzidos e consultados para assegurar o cuidado da saúde dos membros da ordem. O cultivo de ervas e o seu uso para a cura das doenças era uma prática comum. Várias poções eram cuidadosamente manipuladas nas boticas dos monastérios e compartilhadas com a população que se dirigia aos monastérios em busca de cuidados médicos. Os monges beneditinos eram os mais atuantes na prática da medicina, mas isto não era bem visto pelo papado que tentou inibir o seu exercício através de decisões conciliares.

De acordo com Dulce Amarante dos Santos em seu artigo Os saberes da medicina medieval (2013) pode-se identificar três etapas na constituição da história da medicina ocidental entendida como a 
[..] área de saber voltada tanto para a criação de teorias explicativas do funcionamento do corpo humano (teórica) quanto dirigida para a prevenção da saúde e o cuidado terapêutico visando à cura das doenças e o alívio dos males" (AMARANTE DOS SANTOS, 2013: 211)

A primeira etapa corresponderia a Antiguidade quando a teoria médica foi escrita em grego e em latim, destacando-se a ação de Hipócrates e de Galeno que romperam com a relação entre a arte médica, a magia e a religião, e garantindo a ela um campo próprio de reflexão. A Alta Idade Média inaugurou uma segunda etapa protagonizada por Isidoro de Sevilha que, no VII século, em suas Etimologias retomou e sintetizou os principais elementos da teoria galênica. O terceiro momento se caracterizou pela realização e pela difusão das traduções das obras galênicas realizadas em Salerno e em Toledo (AMARANTE DOS SANTOS, 2013: 122).

\section{A monarquia castelhana, os físicos e a saúde do corpo social}

Alguns elementos se encontram no centro das determinações legais em relação à prática da medicina no reino de Leão e Castela: a definição do ofício dos físicos e a regulamentação da sua prática profissional, e a determinação dos tipos de tratamento aceitáveis para as doenças existentes.

As Partidas, por se tratar de um documento de caráter marcadamente enciclopedístico, é a única das fontes selecionadas que demonstra a preocupação de apresentar uma definição acerca do ofício do físico e, mais ainda, do que é a física. $\mathrm{O}$ texto esclarece:

Física, según mostraron los sabios antiguos, tanto quiere decir como sabiduría para conocer las cosas según naturaleza cuáles son en sí, y qué obra hace cada cual en las otras cosas; y por ella lo que esto bien saben, pueden hacer muchos bienes y quitar muchos males, y señaladamente guardando la vida y la salud a los hombres, desviando de ellos las enfermedades por las que sufren grandes lacerias y vienen a la muerte. Y los que esto hacen son llamados físicos, que no tan solamente han de esforzarse por quitar las enfermedades a los hombres, más guardarles aún la salud de manera que no enfermen, y por esto es menester que los que el rey trajere consigo, que sean muy buenos. (SEGUNDA PARTIDA,9,10) 
As Partidas reconheceram a física como um conhecimento antigo e relacionado a manipulação de elementos naturais utilizáveis na prevenção e na cura das enfermidades. Essa obra, redigida no limiar de uma série de mudanças que envolveram a elaboração e a formação dos físicos, não se insere no debate delas decorrentes. A fonte segue a perspectiva já firmada pelo cordobês Averróis (1126-1198) que, em contraposição a forma como a medicina foi tratada no restante do mundo muçulmano, considerou-a uma arte e não uma ciência. Tal distinção se referia a uma percepção diversa da própria elaboração do conhecimento médico.

Enquanto os físicos atuantes no oriente e no norte da África centraram-se mais diretamente na tradução dos textos antigos em busca da elaboração de uma literatura tratadística e glossária, transformando a medicina em uma ciência produzida nas madrassas. Averróis, o maior receptor dos textos aristotélicos no território peninsular, entendendo que a produção do saber partia de uma experiência prática, considerou a medicina como uma arte ensinada e apreendida a partir da atuação cotidiana. A noção de arte, ainda em gestação no século XIII, remetia-se a de habilidade, envolvendo uma oposição entre a "teoria" e a "prática", sem, contudo, se considerar que tal oposição fosse efetivamente precisa, hermética e excludente. Como alertou Jacquart:

\begin{abstract}
Apesar de sua inclinação para a teoria, o próprio Averróis definirá a medicina, no século XII, não como uma "ciência", mas como uma "arte", indo contra o que os autores do Oriente árabe tinham imposto. Essa tomada de posição dependia em parte da influência de Aristóteles, mas também se inscrevia na tradição da medicina de $\mathrm{Al}$ Andalus. Diversos fatores são geralmente evocados pelos historiadores para explicar essa tendência perceptível em outras ciências: a adoção pelos soberanos omíadas do direito malikita, que dava pouco espaço para a especulação; um gosto particular pela natureza que se manifesta desde o reinado de Abd ar-Rahman I pela criação de um jardim botânico. A medicina de Al-Andalus parece, efetivamente, terse desenvolvido a partir da botânica. (JACQUART,1992:169)
\end{abstract}

O físico era aquele que detinha o conhecimento da física (da natureza) e, graças à importância desse saber para a sociedade, a sua prática deveria ser exercida com responsabilidade e sendo regulamentada pelo monarca.

Antes de prosseguir no entendimento da regulamentação da prática da medicina no reino castelhano, convém considerar o papel que o físico ocupava na sociedade medieval peninsular. De acordo com André Filipe Silva (2016), o ofício do medicus, 
existente desde o período imperial romano entrou em desuso durante a Idade Média, embora o saber médico continuasse a ser visitado sobretudo com a transmissão e a preservação da literatura médica. A partir do século XII, o termo physicus passou a ser utilizado em substituição ao termo medicus. Trata-se, contudo, de uma substituição que vai além das palavras, demonstrando uma alteração de cunho conceitual. A introdução das obras aristotélicas no ocidente, a partir do século XII, conforme apontado anteriormente, representou uma virada na concepção e na forma de produção do conhecimento, cada vez mais relacionada ao uso da racionalidade como instrumento para a sua formulação. Logo, o físico era aquele que detinha um saber bastante específico, elaborado com base na sua observação da realidade através da prática médica e do acesso à literatura médica. Conforme lembrou Silva:

[...] Para Aristóteles, o físico era o filósofo da natureza, conhecedor por excelência do mundo natural, dos seus fenômenos e causas. O físico aristotélico não é um médico, está acima dele, como um cientista racional está acima dos artesãos. Aos princípios particulares dos artistas, contrapõemse as verdades e as leis universais da Ciência. (SILVA,2016:44).

Em conformidade com uma política crescente de centralidade de poder expressa na formulação do direito real, se desenvolveu, em Castela, uma ação coordenada da Coroa no fomento de determinações legais referentes aos cuidados relativos à prática médica, fundamentadas pela concepção organicista de poder. Ao monarca garantia-se não só o poder, mas também a responsabilidade de zelar pela saúde dos seus súditos regulamentando a atuação daqueles que praticavam a medicina não só curativa, mas também preventiva.

As doenças eram entendidas como um mal que assolava tanto o corpo físico quanto o corpo social. $\mathrm{O}$ mal era algo que deveria ser evitado e extirpado por trazer o caos para a sociedade. Tal percepção encontra-se na base das determinações legais e explica a sua existência. Como as leis tinham a função de evitar a proliferação do mal punindo aqueles que cometessem "erros", o exercício da física fazia-se necessário para manter a integridade dos súditos.

A tradição médica medieval, conforme visto anteriormente, se baseou sobretudo nas obras de Galeno de Pérgamo (129-217) e dos estudos do grego Hipócrates (460-337 
a. C.). A obra de Galeno se inseria em uma literatura médica produzida nos séculos I e II no Império Romano e tinha como preocupação fundamental entender o funcionamento do corpo humano a fim de cuidá-lo, preservá-lo e, assim, vencer, mesmo que parcamente, a sua mortalidade.

Em linhas gerais, a teoria galena definia os elementos da natureza como concebidos através de quatro elementos: terra, fogo, água e ar. Estes circulavam nos seres humanos através de quatro qualidades (calor, secura, frio e umidade) que se relacionavam aos quatro humores existentes: o sanguíneo (calorosos e amável), o fleumático (apático e lento), o bilioso ou colérico (agressivo e sisudo) e o melancólico (deprimido e triste). A identidade dos elementos constitutivos do universo (macrocosmo) fazia-se representar no corpo humano (microcosmo) e as doenças eram entendidas como resultantes do desequilíbrio dos humores.

Aliado ao saber médico, no âmbito do discurso teológico cristão, difundiu-se a noção de que as doenças eram manifestações diretas do mal da alma no corpo físico. Dessa forma, o doente só alcançaria a cura de fato quando reequilibrasse a sua alma purgando o seu pecado através do exercício da sua espiritualidade, sendo o tratamento dispensado a ele um instrumento para auxiliá-lo no restabelecimento da pureza do seu corpo. Não sem fundamento no imaginário social ocidental, então, os monges foram visto, sobretudo até o século XII, como o aqueles que poderiam oferecer aos que os procurassem o tratamento necessário aos males do corpo.

Dada à importância que o ofício dos físicos tinha na preservação do corpo social cabia ao monarca, então, regulamentar o seu exercício desde a formação desses profissionais até a sua remuneração, passando pelas questões específicas da prática médica. Antes, contudo, de se considerar essas questões, é preciso refletir sobre o acesso que a população tinha aos cuidados médicos.

Os saberes medicinais não eram do domínio somente daqueles denominados físicos. Os cirurgiões e os barbeiros, de origens étnica e religiosa diversas, formaram, ao longo do século XIII, uma rede de assistência à saúde das municipalidades por quem tinham a sua atividade estimulada e regulada. No território peninsular era frequente que cristãos, judeus e muçulmanos exercessem a medicina, agindo no cotidiano das comunidades em troca de um pagamento. Além disso, as ordens religiosas ofereciam auxílio médico à população dos municípios e das áreas rurais e contavam com o apoio 
dos monarcas para essa prática. A cidade de Burgos, por exemplo, tornou-se por determinação de Afonso X uma sede episcopal. A igreja de Santa Maria tornou-se o centro da nova sede e ao seu lado foi erguido o palácio do bispo. O monarca destinou recursos para a construção do primeiro hospital-albergaria que recebia quantias diárias originárias dos impostos pagos pela comunidade judaica local (RIU RIU,1985:267).

Dulce Amarante e outros estudiosos da história da medicina identificaram o período dos séculos XI ao XIII como o momento em que se deu, no ocidente, "[...] a difusão e a institucionalização de uma medicina fundamentada em um saber teórico e submetida a um controle dos seus práticos." (AMARANTE DOS SANTOS, 2014, 124). Essa institucionalização do saber médico, que regulou o exercício da sua prática e a sua difusão, é explicável: pela pressão crescente das monarquias no sentido de organizar e de regulamentar os ofícios de uma maneira geral; pela determinação do papado, expressa nas decisões concilares tomadas em Rheims (1131) e de Paris (1212), no sentido de proibir que os clérigos exercessem a medicina em troca de pagamentos; e pelas epidemias que se tornaram mais frequentes em decorrência da ampliação demográfica experimentada no ocidente medieval.

No que se refere à formação dos físicos o que fica claro na leitura dos códigos selecionados é que a física era uma arte que se adquiria através do aprendizado com um outro físico que estava autorizado a cobrar pelo conhecimento ensinado. $\mathrm{O}$ conhecimento da física era um saber bastante valorizado e não disponível àqueles que não pudessem pagar por ele.

Ao tratar da influência do galenismo no ensino da medicina em Salamanca, no século XV, Luis Garcia Ballester, considerou que não havia indícios documentais sólidos que retificassem a existência de um ensino sistemático da medicina nesse centro universitário. Garcia Ballester chamou a atenção para o fato de que não é perceptível uma produção consistente em torno da medicina, o que seria explicável pelo fato de que a inserção dos estudos das obras de Galeno foi retardada nesse centro universitário graças a sua dependência em relação à Coroa, à forte influência que os cabildos catedralícios ofereciam sobre ela e ao fato de ele ser sustentado pelos dízimos eclesiásticos. A pressão centralizadora da Coroa e da igreja castelhana, para Garcia Ballester promoveram um certo atraso dos estudos da medicina em Castela, que será ampliado somente no século XIV. Ballester afirma: “[...] No obstante, la primera noticia 
que tenemos de un profesor de medicina en Salamanca data de poco antes de 1363" (GARCIA BALLESTER, 2000:12), quando foi possível identificar uma espécie de ordem de pagamento do rei destinado a um professor de física.

Infere-se, através das informações disponibilizadas por Garcia Ballester e pela leitura das fontes, que a regulação da formação dos físicos castelhanos no século XIII não necessariamente passava pela universidade de Salamanca, sendo a estratégia mais frequente de formação, a que se dava através de um profissional para o outro, ou seja, em Castela, no século XIII, a física ainda não era um saber exclusivamente universitário, sendo encarada mais como um ofício do que necessariamente como uma arte.

No contexto de elaboração do FJ, o código mais antigo analisado aqui, a imprecisão quanto à formação dos físicos estava presente, mas a monarquia já se dispunha a regular a sua prática tabelando o pagamento deste ofício. O FJ estabelecia que "El que ensenare á alguno su arte, haya 12. sueldos por su trabajo." (FJ, 11, 1, 7). Levando-se em consideração a quantia estabelecida, é possível identificar o quanto esse ofício era valorizado e provavelmente pouco acessível à maioria da população.

Nas fontes analisadas aqui não há determinação quanto à forma como os físicos adquiririam o conhecimento da sua arte, mas nota-se o cuidado de estabelecer algum tipo de chancela legal ou profissional àqueles que exerceriam esse ofício. O FR determinava que:

Nungun ome non obre de física, si non fuer ante provado por buen físico por los otros Buenos físicos de la villa ô ovicre de obrar, et por otorgamiento de los alcalles: et sobresto aya carta testimonial de conceio: et esto mismo sea de los maestros de las llagas" (FR,IV, XVI,1).

Os físicos e os mestres das chagas, então, só poderiam exercer a medicina se contassem com a aprovação dos demais físicos da vila e com a permissão legal dos alcaides, expressa em uma carta testemunhal do conselho. Nota-se uma ação mais incisiva da monarquia castelhana no sentido da regulamentação da prática médica conforme a sua política de centralidade avançava no nível do reconhecimento da sua autoridade nas esferas municipais. O FB determinava que: 
Ningun omne non obre de física, si non delas plagas, fuere prouado ante por buen físico, por los otros buenos físicos dela uilla do ouiere de obrar. E por otorgamiento delos alcaldes. e sobresto aya carta testimonial del conceio. (FB,IV,16)

A física não mais era entendida pela coroa castelhana como um saber a ser transmitido de um físico a outro de uma maneira informal, mas sim como um conhecimento elaborado que precisava ser provado pelo físico diante dos seus pares, a fim de, com o seu aval, o aspirante conseguir alcançar a licença oficial específica para o exercício do ofício. Das fontes analisadas somente o FR atribuiu penalidades específicas àqueles que exercessem indevidamente o ofício de físico. A lei determinava que: “[...] et si alguno obrare ante que fuer provado e otorgaldo, asi como sobredicho es, peche ccc sueldos al rey" (FR,IV,XVI,1). Tratava-se, portanto, de uma pena pecuniária, que implicava no pagamento de trezentos soldos aos cofres régios, como uma compensação ao rei pelo desrespeito ao corpo social e à autoridade monárquica.

Os físicos tinham a liberdade de tratar com os seus pacientes as formas de pagamento adequadas, contudo a Coroa, através do FR e do FB, reservava para si o direito de determinar que o paciente e os seus parentes estariam isentos de pagar pelo serviço prestado caso a cura da doença não fosse alcançada no prazo previsto, como previa o FB, ou o paciente viesse a falecer, como determinou o FR. As fontes indicam:

Sy algun físico o maestro de llagas tomare alguno em guarda a pleyto que lo sane, e ante que sea santo moriere de aqueça enfermediar, non pueda demandar el precio que avie tajado: et eso mismo sea si puso de lo sanar a plazo sennalado, e non lo sanó. (FR,IV,XVI,2).

$\mathrm{Si}$ algun fisico o maestro de lagas tomare a alguno em guarda a pleyto que lo sane. e si ante que sea sano se muriere daquella enfermedat. non puda demandar el precio que auie taiado. e esso mismo sea. si puso de sanarlo a plazo sennalado e non lo sano (FB, IV,16).

Já no FJ, anterior ao FR e ao FB, não havia esse tipo de determinação. A tendência deste fuero era a preservação da atuação dos físicos, resguardando-os das possíveis vinganças que viessem a enfrentar pelo exercício da sua profissão. De acordo com esse código: "El Físico no pueda ser preso em la cárcel, aunque no sea conócido, sino es por homicidio : y el que debiere algo dé buen fiador." (FJ, 11, 1, 2). Logo, os físicos não poderiam ser presos pelo exercício do seu ofício, somente se cometessem um homicídio 
ou por dívida. Cabe considerar, contudo, que a lei não estabelece com precisão em que circunstâncias a acusação de homicídio poderia se dar, o que poderia permitir que a parte ofendida utilizasse a acusação de homicídio como uma forma de alcançar algum tipo de compensação por um tratamento mal executado pelo físico, ainda mais no contexto do FJ onde as definições processuais não estavam precisadas. Estabelecer uma certa proteção jurídica para os físicos era provavelmente uma forma de a Coroa impedir que eles estivessem à mercê da autoridade dos governantes locais, em grande parte sustentada pelo direito comum.

Aos físicos era garantida a liberdade de tratar com os seus pacientes as formas de pagamento relacionadas ao tratamento oferecido. Contudo, de acordo com o determinado no FR e no FB, só receberiam a quantia acertada se conseguissem, de fato, curar a doença. Os dois fueros determinaram medidas neste sentido:

\footnotetext{
Antes de concertarse el Físico con el enfermo y de asegurar su haber por razón de asistencia y curación, ha de ver y conocer la enfermedad ó dolor): tratada su sanidad, debe procurarla quanto mas pueda; y si muriese, nada haya de lo pactado, ni suscite queja de una parte contra la otra. (FJ,11,1,4)
}

Identifica-se também um cuidado da lei em determinar as normas a partir das quais os tratamentos deveriam ser realizados. O físico deveria se responsabilizar pelo tratamento, demonstrando o conhecimento necessário para desenvolvê-lo, inclusive pesquisando as melhores medidas profiláticas disponíveis, conforme determinava o FJ e alertava as Partidas: "[...] Y los que esto hacen son llamados físicos, que no tan solamente han de esforzarse por quitar las enfermedades a los hombres, más guardarles aún la salud de manera que no enfermen" (SEGUNDA PARTIDA, IX,10).

A regulamentação da prática médica era uma preocupação tão efetiva da Coroa que os códigos determinavam também as formas de tratamento aceitáveis.

A única forma de tratamento identificável no FJ é a sangria. Já no FR é possível encontrar menções, além da sangria, os tratamentos de "[...] trajar, fender ou sacar osso, queimar ou meleciar [..]" foram indicados. Estes mesmos tratamentos foram propostos no FB. Nas Partidas, há a menção de tratamentos não considerados nas fontes anteriores: a manipulação de pedras, o uso de poções, de ervas e de escamonias (ervas medicinais purgativas). 
As sangrias eram o tipo de tratamento mais usual na medicina medieval, principalmente na tradição monástica. Elas eram realizadas a partir de três formas distintas: pela flebotomia, por meio de ventosas e pelo uso das sanguessugas A flebotomia, extração do sangue com fins terapêuticos, se dava como uma forma de equilibrar os humores ou com fins cirúrgicos, sendo prevista nas regras monásticas e funcionando como um instrumento na promoção do reequilíbrio corporal.

O uso da sangria como tratamento para as doenças partiu do princípio disposto na teoria galênica que se baseava no fluxo e no refluxo dos espíritos (pnêuma) e do sangue através das artérias e dos nervos, e identificava o coração como o centro do calor e os pulmões como órgãos de resfriamento. Quando o sangue e o pnêuma alcançavam o cérebro através da grande circulação, se transformavam em um espírito racional que se distribuía pelo corpo através dos nervos.

O sangue era entendido, portanto, como uma das substâncias vitais que animavam o homem, logo o desequilíbrio do corpo humano, causador das doenças, encontrava-se diretamente relacionado à intensidade da sua circulação. Sangrar o doente era a forma mais eficaz para fazer com que o mal se esvaísse do corpo e o equilíbrio do organismo fosse restituído. Sobre a influência da tradição galênica no uso da sangria pela medicina medieval, Raymondo Vieira em sua obra Raízes históricas da medicina ocidental (2012) afirmou:

\footnotetext{
Para Galeno, a interpretação das enfermidades girava basicamente em torno das alterações dos humores localizados nas distintas partes do corpo. Também o tratamento teria como principal objetivo proporcionar os meios que ajudassem o organismo a corrigir os transtornos humorais. Em virtude disso, recomendava dietas específicas para ajudar na "limpeza de sucos putrefatos" e frequentemente para purgar ou limpar o organismo, utilizava a sangria. (VIEIRA,2012:375)
}

O uso frequente da sangria, dependendo do quadro clínico do doente, contudo, poderia gerar um maior enfraquecimento do organismo já enfermo e o consequente agravamento da doença. Sobre essa forma de tratamento, o FJ determinou: 
El que sangre á hombre y lo debilite, debe pagarle 1 50. sueldos: si le cause la muerte, sea puesto en poder de sus parientes para que hagan de él lo que quisieren ; y siendo siervo el muerto ó debilitado con la sangría, entregue otro tal á su dueño. (FJ,XI,1)

A sangria foi a único procedimento médico sobre o qual o FJ legislou, o que demonstra a importância e a frequência com que essa prática era utilizada. $O$ uso inadequado da sangria implicava em que quem a realizasse, e não há especificação de que esse procedimento fosse realizado por um físico, deveria ser penalizado com o pagamento de uma pecúnia bastante significativa caso o paciente ficasse muito enfraquecido. Em caso de morte do paciente, não houve a especificação de uma pena para o acusado que, em última instância perderia a sua liberdade e estaria à mercê dos familiares do paciente responsáveis por decidir a forma como ele deveria ser punido. Essa abertura na lei pode ser entendida como uma legitimação, pela Coroa, da tradição jurídica da vingança privada nos casos extremos que implicavam na perda de um familiar. Contudo, tais determinações só eram válidas para os homens livres.

Confirmando uma tendência presente nos vários códigos produzidos na Idade Média, o FJ penaliza, de forma diferenciada os homens livres e os servos, já que o estado de servidão implicava na perda da autonomia jurídica e determinava que o senhor fosse considerado a parte ofendida e consequentemente a ele fossem dedicadas as medidas compensatórias legais. Logo, aquele que enfraquecesse ou levasse à morte um servo pelo mal emprego da sangria deveria dar ao senhor um outro servo que substituísse a mão de obra perdida ou inutilizada. $\mathrm{O}$ uso indevido da sangria também foi penalizado pelo FR com a aplicação de penas pecuniárias e penas corporais, como a perda da liberdade, estando o corpo e os bens do culpado à mercê do rei, conforme observável no trecho abaixo:

[...] et ninguno dellos non sea osado de trajar, nin de fender, nin de sacar hueso, nin quemar, nin de melecinar em ninguna guisa, nin de facer sangrar et si alguno lo ficiere, peche $\mathrm{x}$ maravedis al marido de sul a muger fuere casada, sin non al mas propinco pariente que oviere: et si alguno obrare ante que fuer provado e otorgaldo, asi como sobredicho es, peche ccc sueldos al rey, e si matar o lisiar a ome o a muger, el cuerpo e lo qe oviere sea a merced del rey, so fijos non oviere: et si fijos oviere, hereden sus fijos ela ver, e el cuerpo sea a merced del rey. (FR, IV,XVI,1) 
Conforme a lei mencionada, o FR também punia os físicos e os mestres de las chagas, os cirurgiões, que promovessem qualquer tipo de tratamento de fraturas ósseas. Essa lei remete, portanto, à regulamentação da prática cirúrgica que, na Idade Média, poderia ser praticada pelos físicos e pelos cirurgiões. Ruggero de Frugardo inovou na realização de cirurgias nas amídalas, nas hérnias, na vesícula e nos ferimentos da cabeça, do pescoço, dos nervos, das fraturas e das luxações, como também na utilização de uma mistura anestésica, composta por ópio, hiosciamina, suco de papaverina negra, mandrágora e outros componentes, utilizada durante o procedimento (VIEIRA,2012: 436).

O cuidado das fraturas era uma questão particularmente delicada em um contexto em que boa parte dos ofícios desempenhados dependia diretamente do pleno funcionamento corporal. Mulheres e homens precisavam estar aptos a desenvolver suas tarefas agrícolas, artesanais e, no caso masculino, militares. Um guerreiro que tivesse um osso mal tratado ou extraído poderia ver a sua capacidade de luta seriamente comprometida, o que poderia implicar na perda do seu status social e do seu ganho econômico. Não foi sem sentido, então, que a Coroa julgou necessário legislar sobre esse tipo de cirurgia em específico.

O conhecimento cirúrgico estava presente na tradição médica muçulmana conforme mencionado anteriormente, ele era praticado nos hospitais, onde os casos dos pacientes internados serviam como oportunidade de estudo, como ocorre até hoje. Essa forma de tratamento foi largamente difundida nos escritos de Avicena e de Albucasis (956-1013), médico cordobês e autor da enciclopédia de medicina Al-tasreef liman ajiza an al-taaleef, cuja a sessão referente à cirurgia foi traduzida por Gerardo de Carmona, no século XII. Albucasis deixou catalogado cerca de trezentas doenças enunciando as suas formas de tratamento, com a descrição dos procedimentos e dos instrumentos cirúrgicos. De acordo com Jacquart:

[... ] A parte dedicada à cirurgia fez o renome de az-Zahrawi: ela abria um novo caminho que o Ocidente não deixou de explorar, graças à representação figurada de instrumentos, à importância dada à cauterização, à descrição precisa do desenrolar das intervenções cirúrgicas (JACQUART,1992:170). 
A lei proposta no FR estabelecia, então, o pagamento ao rei de uma pesada pecúnia e a perda da liberdade e dos bens daquele que realizasse a cirurgia óssea de forma indevida, tanto em um homem quanto em uma mulher, promovendo lesões ou a morte do paciente. Essa lei exprime o espírito organicista que envolveu o projeto monárquico afonsino, onde o rei, como o cabeça do reino, seria a parte mais ofendida com a inutilidade ou a perda de um dos seus membros, que comprometeriam o ordenamento e a produtividade social.

Um outro ponto interessante proposto no FR se refere aos cuidados com a saúde feminina condenando à penalização, sobretudo pecuniária, aqueles que realizassem qualquer tipo de procedimento cirúrgico ósseo, sangrias ou cuidados com feridas nas mulheres que levassem a lesões ou a incapacidade. A pecúnia deveria ser paga ao marido, se a mulher fosse casada, ou ao seu parente mais próximo, caso não o fosse.

O cuidado da lei com o corpo feminino parece relacionar-se à capacidade reprodutiva que ele possui, visto serem as mulheres as responsáveis pela reprodução física da sociedade; à capacidade produtiva já que as mulheres representavam uma boa parte da mão de obra utilizada nas cidades, principalmente no setor artesanal; e à uma questão estética, visto que um procedimento mal executado poderia comprometer diretamente a vida da mulher, comprometendo a sua inserção e o seu status na comunidade. Entretanto, apesar de esse cuidado legal suscitar o entendimento de uma certa valoração do corpo feminino, a leitura de uma das leis do FB indica a falta de autonomia da mulher na decisão quanto a aceitação do procedimento médico adotado, pois eles só poderiam ser executados com a autorização do marido. Conforme estabeleceu a lei: "[...] e ninguno dellos non sea osado de taiar. nin de fender. nin de sacar huesso. nin de quemar. nin de melezinar en ninguna guisa. Nin de fazer sangrar a ninguna mugier sin mandado de so marido (FB, IV, 16).

Das fontes aqui analisadas, as Partidas são aquelas que permitem a identificação de um maior número de tratamentos médicos. Nelas há referências diretas à manipulação de pedras, ao uso de poções, de ervas e de escamonias, ervas medicinais com efeito purgativo, e também a proposição da pena referente a de homicídio para aqueles prescrevessem indevidamente o uso dessas substâncias.

O uso das ervas e das pedras com fins curativos era uma prática comum na medicina medieval, tanto a desenvolvida no ocidente quanto no oriente. A difusão do 
aristotelismo inspirou os homens medievais a ampliar a exploração dos recursos naturais para fins curativos, em um movimento crescente de experimentação da sua aplicação na cura das doenças e na sua prevenção. $O$ uso da prática médica como instrumento para a elaboração do tratamento para as doenças fez parte do cerne da medicina muçulmana. Maria Conforti (2010) reconheceu que grande parte do conhecimento difundido nas escolas árabes se inspirou diretamente nas tradições persa e indiana, favorecendo a elaboração de manuais e de compêndios médicos.

O material produzido era particularmente enriquecedor para o saber médico na medida em que os tradutores não só traduziram do siríaco para o árabe o nome de boa parte das substâncias e das plantas, como também encontravam termos e componentes equivalentes no léxico ocidental àqueles da tradição médica oriental. A tradição da farmacologia árabe se pautou na elaboração de listas de fármacos experimentados com as suas devidas utilidades e "[...] Como regra geral, prefere-se a terapêutica farmacológica à cirurgia - um uso depois muito criticado pela cirurgia do Renascimento - e confia-se, principalmente, nos fármacos simples." (CONFORTI,2010:423). Sobre a prescrição indevida dos fármacos, a Sétima Partida determinou, acerca da administração da escamonia, uma bebida com efeitos purgativos:

Otrosí decimos que los boticarios que dan a los hombres a comer o a beber escamonia u otra medicina fuerte sin mandamiento de los médicos, si alguno bebiéndola muriese por ello, debe tener el que la diese pena de homicida en la manera que dijimos de los físicos y los cirujanos (SÉTIMA PARTIDA,VIII,6).

A figura do boticário, aquele que sabe misturar as substâncias manipulando poções, fica evidente nessa lei que, ao mesmo tempo, determina a sua subordinação aos físicos, já que não poderiam prescrever nenhuma poção aos pacientes sem a recomendação deles. Caso o paciente viesse a óbito em decorrência desse tratamento, o boticário incorreria na mesma pena referente à prática do homicídio.

Uma outra lei presente na Sétima Partida condena aos físicos que dessem [...] tan fuerte medicina o la que no debía a algún hombre o a alguna mujer que tuviese en guarda" (SÉTIMA PARTIDA,VIII,6) e que resultasse na morte do enfermo. A mesma 
lei também menciona os homens ou mulheres que "[...] diese hierbas o medicina a otra mujer porque se empreñase" (SÉTIMA PARTIDA,VIII,6) causando a morte da mulher.

Torna-se evidente, na leitura das fontes, que vários personagens atuavam na prática da medicina no reino castelhano, ocasionando uma certa confusão de papéis que a Coroa pretendia corrigir investindo na verificação das habilidades dos físicos e inibindo o exercício da prática médica aos outros personagens tradicionalmente reconhecidos pela população. Inclusive, nota-se a presença de mulheres como praticantes desse saber médico, principalmente aquele relacionado à concepção.

O recurso aos boticários e às mulheres conhecedoras de ervas evidencia também o hábito da população de recorrer a um tratamento medicinal menos oneroso do que aquele oferecido pelos físicos. É possível notar uma certa tolerância legal da Coroa em relação àqueles que ofereciam esse tipo de tratamento e que já faziam parte da tradição médica do reino, desde que eles realizassem a sua atividade sem causar a morte daqueles que tratavam.

Não só estava previsto na lei o uso das substâncias vegetais como formas de tratamento, a Coroa estava atenta também ao uso das substâncias minerais como ingredientes para a realização de poções curativas. A Quinta Partida tem uma lei dedicada ao uso incorreto das pedras para o tratamento medicinal, onde se condenava aos físicos, aos cirurgiões e aos albeítares (veterinários) que recebessem dos seus pacientes pedras preciosas para serem utilizadas em seu tratamento e, em não sabendo manuseá-las terminassem por quebrá-las “[...] debe pagar la estimación de ella a bien vista de hombres buenos y conocedores de estas cosas" (QUINTA PARTIDA,VIII,10).

$\mathrm{O}$ uso das pedras como formas de tratamento fazia parte do pensamento analógico medieval, onde as mais variadas criaturas do mundo (a fauna, a flora, o mundo mineral) eram entendidas como signos dados por Deus aos homens, que tinham a função de decifrar e de compreender o significado oculto por trás deles. A cor e a forma das pedras eram relacionadas ao seu potencial curativo e esse tipo de informação era registrado nos lapidários, como o que foi traduzido no scriptorium afonsino, diretamente do árabe. A tradução dos lapidários era bastante trabalhosa, pois implicava na adequação dos termos originais locais para o árabe. 
Durante o reinado de Afonso X um lapidário foi traduzido do árabe e nele era possível identificar a caracterização das pedras, os seus usos medicinais e os locais onde elas poderiam ser encontradas, dentre outras informações. O interessante do Lapidário de Afonso $\mathrm{X}$ é que imerso na concepção corrente no medievo da presença do macrocosmo no microcosmo, estabelecia a utilização das pedras sob os auspícios das constelações astrológicas para a potencialização dos seus efeitos curativos. No Lapidário, a medicina, a astrologia e a magia se uniam tanto para a promover a cura e a prevenção das doenças, através sobretudo da elaboração de poções, como também para oferecer um efeito anestésico em meio a um procedimento cirúrgico.

\section{Conclusão}

Acreditamos que as considerações feitas aqui sustentam a conclusão de que, no século XIII, os monarcas castelhanos, atendendo às demandas do seu projeto político de busca pela centralidade, utilizaram referências da cultura intelectual e da tradição jurídica medievais para referendar e basear os mecanismos legais que regeriam a comunidade castelhana e a sua relação com o monarca, estando o ordenamento quanto a forma como a saúde física dos súditos seria tratada entre as preocupações e as determinações do poder real, expresso nas fontes jurídicas selecionadas para análise. Desta forma, mostrava-se necessário determinar os limites da atuação dos físicos e os procedimentos médicos legítimos.

\section{Referências Bibliográficas}

FUERO JUZGO. Edición de la Real Academia Española, 1815. In: Colección Leyes Históricas de España. Estudio preliminar de Santos. M. Coronas. Madrid: Imprenta Nacional de La Agencia Estatal Boletín Oficial del Estado, 2015.

FUERO REAL de Alfonso X El Sabio. Edición de La Real Academia de la Historia, 1836. In: Colección Leyes Históricas de España. Estudio preliminar de Antonio Pérez Martín. Madrid: Imprenta Nacional de La Agencia Estatal Boletín Oficial del Estado, 2015. 
LAS SIETE PARTIDAS (Disponível em CD ROM). O’NEILL,J. (org.). Eletronic textes and Concordances of the Madison Corpus of Early Spanish Manuscripts and Pritings. The Hispanic Seminary of Medieval Studies. Madison and New York, 1999.

FUERO DE BURGOS (Disponível em CD ROM). O'NEILL,J. (org.). Eletronic textes and Concordances of the Madison Corpus of Early Spanish Manuscripts and Pritings. The Hispanic Seminary of Medieval Studies. Madison and New York, 1999.

\section{Bibliografia}

AMARANTE DOS SANTOS, D. Os saberes da medicina medieval. História Revista, Goiânia, v. 18, n. 1, p. 121-134, jan. /jun. 2013.

BEJDER, M. S. O rei e a lei: definições do poder real na análise do Fuero Juzgo. Anais eletrônicos do XIII Encontro de História Regional ANPUH-RIO. Seropédica: 2008. Disponível em: https://anpuh.org.br/index.php/encontros-regionais/encontrosanpuh-rio/xiii-encontro-regional-de-historia-2008-rj ; acesso em 12 abril 2020

BOUSTANI, F. A circulação do sangue entre o Ocidente e o Oriente, a história de uma descoberta. Rio de Janeiro: Editora UFRJ, 2018.

CONFORTI, M. Do texto à prática: a farmacologia, a clínica e a cirurgia no mundo islâmico In: ECO, Umberto. Idade Média - Bárbaros, cristãos e muçulmanos. Alfragide: Dom Quixote, 2010.

GARCÍA BALLESTER, L. Galenismo y enseñanza médica en la universidad de Salamanca del siglo XV. DYNAMIS. Acta Hisp. Med. Sci. Hist. Illus. 2000, 20, 209-247. Disponível em : https://ddd.uab.cat/pub/dynamis/02119536v20/02119536v20p209.pdf

Acesso em 12 abril 2020

GROSSI, P. A Ordem Jurídica Medieval. São Paulo: Martins Fontes, 2014.

HESPANHA, A. M. Cultura jurídica europeia. Síntese de um milênio. São Paulo: Almedina, 2003.

KOCKA, J. Comparison and beyond. History and Theory. 42: 39-44, feb. 2003. Tradução de Maria Elisa da Cunha Bustamante. 
IGLESIA FERREIRÓS, A. Alfonso X el Sabio y su obra legislativa. Anuario de

Historia del Derecho español. n 50. 1980. p. 531-561. Disponível em https://www.boe.es/biblioteca juridica/anuarios_derecho/abrir_pdf.php?id=ANU-H1980-

10053100562 ANUARIO_DE_HISTORIA_DEL_DERECHO_ESPA\%C3\%910L_Alf onso_X_el_Sabio_y_su_obra_legislativa:_Algunas_reflexiones;

Acesso em 12 abril 2020

JACQUART, D. A escola de tradutores. In: CARDAILLAC, L. (org.). Toledo, séculos XII-XIII. Muçulmanos, cristãos e judeus: o saber e a tolerância. Rio de Janeiro: Jorge Zahar, 1992.

JACQUART, D. A medicina árabe e o Ocidente. In: CARDAILLAC, L. (org.). Toledo, séculos XII-XIII. Muçulmanos, cristãos e judeus: o saber e a tolerância. Rio de Janeiro: Jorge Zahar, 1992.

RÉMOND, R. Por uma História Política. Rio de Janeiro: Editora FGV, 2003.

RIU RIU, M. Edad Media (750-1500). Manual de Historia de España. v. 2. Madrid: Espasa Calpe, 1985.

VIEIRA, R. M. Raízes históricas da medicina ocidental. São Paulo: Editora FapUnifesp, 2012.

SALVADOR, N. M. El Intelectual. In: VALDEÓN, J. et al. La Espanã de Alfonso X. Cuadernos de História 16. n. 13. Madrid: Grupo 16, 1985. Disponível em https://saladehistoria.net/biblioteca-digital/historia-16/cuadernos-de-historia-16/;

acesso em 12 abril 2020.

SCHIOPPA, A. P. História do Direito na Europa. Da Idade Média à Idade Contemporânea. São Paulo: Martins Fontes, 2014.

SILVA, A. F. O da. Físicos e cirurgiões medievais portugueses. Contextos socioculturais, práticas e transmissão de conhecimentos (1192-1340). Porto: CITCEM, 2016. 
VALDEÓN, J. La época. In: VALDEÓN, J. et al. La Espanã de Alfonso X. Cuadernos de História 16. n. 13. Madrid: Grupo 16, 1985. Disponível em https://saladehistoria.net/biblioteca-digital/historia-16/cuadernos-de-historia-16/ ;

acesso em 20 março 2020

\section{Notas}

\footnotetext{
${ }^{1}$ Serão utilizadas abreviações para referir-se às obras jurídicas no restante do texto. O Fuero Juzgo será abreviado FJ; o Fuero Real, FR; e o Fuero de Burgos, FB.
} 